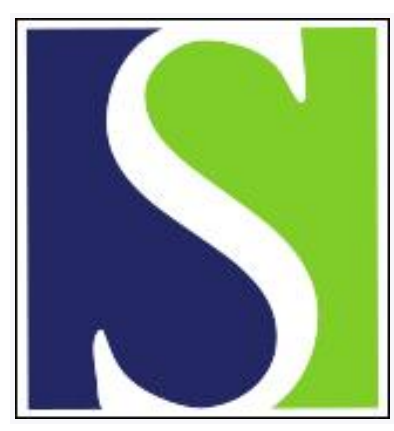

Scand J Work Environ Health 1976;2(4):220-224

https://doi.org/10.5271/sjweh.2801

Issue date: Dec 1976

\title{
Exposure to trichloroethylene III. Psychological functions.
}

by Gamberale F, Annwall G, Olson BA

Key terms: behavioral effect; experimental psychology; exposure; psychological function; trichloroethylene

This article in PubMed: www.ncbi.nlm.nih.gov/pubmed/1019596

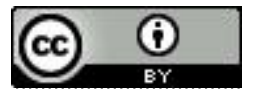




\title{
Exposure to trichloroethylene
}

\section{Psychological functions}

\author{
by FRANCESCO GAMBERALE, Ph.D., GÖREL ANNWALL, B.A., and \\ BIRGITTA ANSHELM OLSON, M.Sc. ${ }^{1}$
}

\begin{abstract}
GAMBERALE, F., ANNWALL, G., and ANSHELM OLSON, B. Exposure to trichloroethylene: III. Psychological functions. Scand. $j$. work environ. \& health 4 (1976) $220-$ 224. The effect of exposure to the solvent trichloroethylene (TRI) on the performance of tests of numerical ability, reaction time (simple and choice), and short-term memory was studied in 15 healthy male subjects. The subjects were tested individually on three different occasions during exposure to 540 and $1,080 \mathrm{mg} / \mathrm{m}^{3}$ of TRI in inspiratory air and under control conditions, respectively. At predetermined times during the three 70-min exposure periods, samples were taken of the subjects' alveolar air. Neither the reaction time tests nor the short-term memory test showed any signs of performance decrement during exposure to TRI as compared to those administered under control conditions. However, a statistically significant decrement in performance was obtained on the test of numerical ability during exposure to TRI. The results as a whole indicate that there should not be any risk of an acute effect on central nervous functions at concentrations which do not considerably exceed the Swedish threshold limit value for the solvent $\left(160 \mathrm{mg} / \mathrm{m}^{3}\right)$.
\end{abstract}

Key words: trichloroethylene, experimental psychology, psychological functions, behavioral effects.

Trichloroethylene (TRI) is a common solvent that has been the subject of extensive study. However, research conducted to date in laboratory examinations of the effect of TRI on man's central nervous functions has led to partially contradictory results. Thus Stopps and McLaughlin (11) found that a subject exposed to $540 \mathrm{mg} / \mathrm{m}^{3}$ of TRI for $2.75 \mathrm{~h}$ failed to display any sign of impaired performance capacity in a number of psychomotor tests. However, a progressive decline in performance with increasing TRI concentrations was noted

1 Work Psychology Division, Department of Occupational Medicine, National Board of Occupational Safety and Health, Stockholm, Sweden.

Reprint requests to: Dr. Francesco Gamberale, Arbetarskyddsstyrelsen, Arbetsmedicinska avdelningen, Arbetspsykologiska enheten, Fack, 10026 Stockholm 34, Sweden. in the same subject. A more comprehensive study was carried out by Salvini et al. (8), who exposed six subjects to $590 \mathrm{mg} / \mathrm{m}^{3}$ for a $2 \times 4$ hour period. This exposure led to a general impairment in performance on various psychomotor and cognitive tests. The experiment of Salvini et al. was repeated by Stewart et al. (10), who employed a somewhat modified design but the same test instruments. This study produced no unequivocal evidence of impaired functional capacity, and thus the results of Salvini et al. could not be confirmed.

The use of psychological tests in toxicological studies demands the active cooperation of subjects whose motivation should be at a maximum. Results from experimental trials with exposure periods as long as $8 \mathrm{~h}$, as in the experiments by Salvini et al. and Stewart et al., are likely to present methodological problems of 
interpretation because of irrelevant effects such as fluctuations in motivation and variations in circadian rhythm.

The objective of the present study, in view of discrepancies in previous results, was to examine the extent to which man's central nervous functions are affected by acute exposure to TRI.

In our previous studies of various solvents, reviewed in another publication (2), an acute effect was observed already after less than $2 \mathrm{~h}$ of exposure at concentrations at or immediately above the Swedish threshold limit value (TLV) for the respective substance at that time. The present Swedish TLV for TRI $\left(160 \mathrm{mg} / \mathrm{m}^{3}\right)$ is considerably lower than the $590 \mathrm{mg} / \mathrm{m}^{3}$ of TRI used in the aforementioned studies. Such concentrations are probably only encountered in Swedish work environments during brief periods of exposure.

In view of the preceding information the present study was conducted according to the experimental design and exposure levels used in the studies by Salvini et al. (8) and Stewart et al. (10). However, the effects were studied after briefer periods of exposure.

\section{METHOD}

\section{Subjects}

Fifteen healthy men from 20 to 31 years of age participated as subjects. All were employees of the Department of Occupational Medicine.

\section{Design and procedure}

The subjects were divided at random into three equally large groups. They were studied individually during two sets of experimental conditions with exposure to approximately $540 \mathrm{mg} / \mathrm{m}^{3}$ (range of variation $521-553 \mathrm{mg} / \mathrm{m}^{3}$ ) and $1,080 \mathrm{mg} / \mathrm{m}^{3}$ (range of variation $1,067-1,093 \mathrm{mg} / \mathrm{m}^{3}$ ) of TRI and during exposure to ordinary atmospheric air. The three different trials were performed for each subject at the same time on three different occasions every other day. The experimental sequence was balanced between the three groups, days, and exposure concentrations according to table 1 .
During each session the subjects were exposed for $70 \mathrm{~min}$. The gas mixture was supplied via a breathing valve with very slight resistance. The taste and smell of the gas was disguised by the insertion of a cannister of menthol crystals into the tube of the mouthpiece of the valve. The concentration of TRI in alveolar air was measured with a gas chromatographic technique every third minute for the first $50 \mathrm{~min}$. In the following $20 \mathrm{~min}$, during which four performance tests were carried out, measurements were made after every test. The same operations and measurements were carried out at all three exposure levels.

The experiments were performed with the subjects seated at a desk. Prior to the first day of experiment they were given an opportunity to practice on all the tests.

Self-estimates of intoxication and mood were collected as the final step following each session. The subjects were asked to assess their own conditions on a 7-point evaluation scale with respect to the following six variables: calm/hurried, active/ passive, relaxed/tense, well-disposed/illdisposed, unaffected/affected, spry/tired. After the second and third measurement sessions each subject was asked if he had been able to notice any difference between conditions with respect to the inspiratory air. The purpose of this question was to study the extent to which the menthol had been effective.

\section{Performance tests}

All performance tests were carried out with the aid of a stimulus-response panel on which stimuli could be administered

Table 1. Experimental design for the $70 \mathrm{~min}$ of exposure to trichloroethylene vapor.

\begin{tabular}{crrr}
\hline \multirow{2}{*}{$\begin{array}{c}\text { Measurement } \\
\text { occasion/day }\end{array}$} & \multicolumn{3}{c}{ Vapor exposure $\left(\mathrm{mg} / \mathrm{m}^{3}\right)$} \\
\cline { 2 - 4 } & Group 1 & Group 2 & Group 3 \\
\hline 1 & 0 & 540 & 1,080 \\
2 & 1,080 & 0 & 540 \\
3 & 540 & 1,080 & 0 \\
\hline
\end{tabular}


and answers recorded electronically. Stimulation was visual, and the subjects answered by touching a switch connected to the respective stimulus. The panel was supplied with 15 stimulus-response units arranged so that they formed three rows and five columns. The switches in the upper two rows were labeled with numerals from 0 to 9 .

The following tests were given in all test sessions in the order in which they appear in the text.

$R T$-Addition $(R T=$ reaction time $)$. The RT-Addition test was conducted so that series of three stimuli, the stimuli lasting $0.4 \mathrm{~s}$ at $0.1-\mathrm{s}$ intervals, were displayed on the numbered part of the panel. The subject had to add the numbers of the respective stimuli as quickly as possible and indicate the correct answer with the aid of the numbered switches. The sequences for the first 4 and the last 32 series were varied at random from test session to test session. Performance capacity was measured as the mean value of the reaction times for the last 32 series.

Simple RT. Only one of the stimulusresponse units on the panel was used for the simple reaction time test. Each subject was instructed to rest his fingertips lightly on the switch and to respond to a light signal by pressing the switch as quickly as possible. The test consisted of a total of 96 stimuli divided into 6 comparable series comprising 16 consecutive stimuli. Each series took about 1 min to perform and the interval between stimuli varied from 1.7 to $5.2 \mathrm{~s}$. Performance capacity was measured as the mean value of the reaction times for all stimuli. Mean reaction time values for each time block (1-min period) were also calculated for an analysis of the change in performance over time.

Short-term memory. In the short-term memory test, series of stimuli, the stimuli lasting $1 \mathrm{~s}$ at $1-\mathrm{s}$ intervals, were displayed on the numbered part of the panel. The subject was instructed to reproduce the sequence of numbers presented upon receiving a signal indicating that the sequence was concluded. The answer was given with the aid of the numbered switches. The subject received 10 dif- ferent series with the number of stimuli increasing from 4 to 10 . The test was used in parallel versions in the different test sessions. The response data were analyzed according to the following two criteria: the number of correctly reproduced stimuli as a percentage of the total number of stimuli and the number of correctly reproduced series as the percentage of the total number of series.

Choice RT. The choice reaction time test was conducted so that series of three stimuli, the stimuli lasting $0.3 \mathrm{~s}$ at $0.1-\mathrm{s}$ intervals, were displayed on the numbered part of the panel. The task of the subject was to identify the number which should be interposed between the other two numbers to form a numerical sequence. The subject supplied the answer by pressing the switch immediately beneath the switch labeled with the number selected. The sequences of the first 5 and 35 subsequent series were varied at random from one test session to another. Performance capacity was measured as the mean value of the reaction times for the 35 last series.

\section{RESULTS}

\section{Concentration in alveolar air during exposure}

The concentrations of TRI in the alveolar air samples taken during the experimental conditions are shown in fig. 1 . The symbols in the figure represent mean values for the 15 subjects. Standard deviations averaged $23 \%$ of the respective mean values. As fig. 1 shows, the increase in alveolar air concentration took place mainly at the beginning of the exposure periods when no performance measurements were made.

The relationship between the TRI concentration in the alveolar air and arterial blood was found to be high (1). This circumstance was in close agreement with previous studies $(1,3,4,5,6)$, in which the concentration, in arterial blood, of substances with poor solubility in blood could be closely approximated on the basis of the concentration in the alveolar air. 


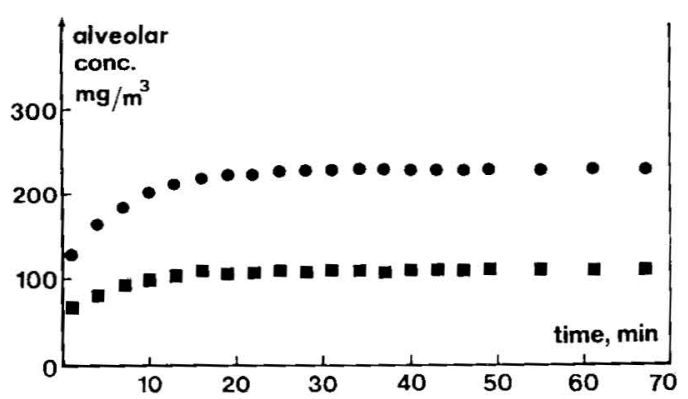

Fig. 1. Concentration of trichloroethylene in alveolar air during exposure to $540 \pm 19 \mathrm{mg} /$ $\mathrm{m}^{3}$ (a) and $1,080+13 \mathrm{mg} / \mathrm{m}^{3}$ (•), respectively, of trichloroethylene in inspiratory air. The symbols in the figure represent mean values for 15 subjects.

\section{Subjective reactions}

The subjects' self-estimates of intoxication and mood following exposure appeared to differ systematically from self-estimates made after the inspiration of ordinary air. An evaluation of the significance of differences between the three conditions was performed with the Friedman two-way analysis by ranks (9). The differences between conditions were consistently nonsignificant when variables were tested individually $(p>0.05)$. On the other hand a significant difference was obtained when the testing was based on the total of six variables $\left(\mathrm{X}^{2}=6.43 ; \mathrm{p}<0.05\right)$. This result would suggest that exposure to TRI had a negative effect on subjective assessment. However, this result is difficult to interpret since, in spite of the precautions taken, nearly half of the subjects could distinguish between exposure and nonexposure.

\section{Performance changes during exposure}

The statistical analysis of the results of the four performance tests was performed with an analysis of variance. The variance analysis model (12) employed was based on a $3 \times 3$ Latin square design with repeated measurements (table 1 ). The model made possible the simultaneous testing for performance differences due to, e.g., dif- ferent degrees of exposure, repeated measurements (training effect), and the interaction between degree of exposure and training. With regard to the Simple RT test, the variance model was modified so that it included the testing of changes in reaction time over time and a test of trend (trend-analysis).

No significant interaction effects between exposure to TRI and training (TRI $X$ T) were found in the analyses. This result facilitated the interpretation of the significance of the two main factors regarding changes in performance during the experiments.

In the RT-Addition test the level of performance varied significantly between the different exposure conditions [ $\mathrm{F}(2.24)$ $=4.35 ; \mathrm{p}<0.05]$ and between successive measurement occasions $[\mathrm{F}(2.24)=19.25$; $\mathrm{p}<0.001]$. The level of performance declined with increased exposure to TRI, whereas repetition of the testing led to a pronounced improvement in performance as a result of the training effect.

In the short-term memory test neither exposure to TRI nor repeated measurements led to any significant changes in performance, nor did exposure to TRI have any significant effect on performance in the Choice RT test. However, the latter test showed a pronounced training effect $[F(2.24)=11.56 ; p<0.001]$. In the Simple $\mathrm{RT}$ test the trend analysis disclosed a significant linear trend over the time block [Tlin. $F(1.120)=27.03 ; p<0.001]$. Therefore reaction time increased successively during the test according to the same pattern as in our previous studies of solvents $(4,7)$. However, neither this change during the course of the test nor the mean performance during the test interacted significantly with exposure to TRI or the measurement sequence.

\section{DISCUSSION}

The present investigation was performed so that we could study the acute effects of TRI on the central nervous functions of man. In many respects the experimental procedure employed was similar to the earlier studies of Salvini et al. (8) and Stewart et al. (10). However, the 
subjects in the present study were exposed for briefer periods of time $(70 \mathrm{~min})$.

A significant impairment in performance attributable to increased exposure to TRI was obtained for only one of the four performance tests used (RT-Addition).

The results as a whole do not provide the basis for any unequivocal conclusion regarding the effect of the studied concentrations of TRI on the psychophysiological functions of man. The fact that exposure failed to induce any measurable change in performance in two psychomotor tests (Simple RT and Choice RT) and in one cognitive test (short-term memory) raises doubts as to whether TRI, at the concentrations employed, has any definite effect on man's psychophysiological functions.

However, the circumstance that one of the tests (RT-Addition) yielded statistical evidence of impaired performance in exposure to TRI should be kept in mind. A detailed analysis of individual subject performance on the test resulted in no alternative explanation for the differences noted. Despite the fact that this test disclosed a pronounced learning effect and the largest individual variation in the battery of tests, the results still point to an effect of exposure.

The studies conducted by Salvini et al. (8) and Stewart et al. (10), which were used as starting points in the present study, resulted in contradictory findings. The former study suggested definite effects ascribable to exposure to TRI, whereas no such effects were found in the latter study. Assuming that the higher TRI concentration in the present study resulted in an uptake of solvent comparable to that produced by the longer exposure in the aforementioned studies, our results would appear to be in general agreement with those obtained by Stewart et al. (10). These results indicate that there should be no risk of acute effects on the central nervous system at concentrations which do not markedly exceed the Swedish TLV for this solvent.

\section{REFERENCES}

1. ASTRAND, I. Uptake of solvents in the blood and tissues of man: A review. Scand. j. work environ. \& health 1 (1975) 199-218.

2. GAMBERALE, F. Behavioral effects of exposure to solvent vapor: Experimental and field studies. In: M. HORVÁTH (ed.), Adverse effects of environmental chemicals and psychotropic drugs (vol. 2). Elsevier Scientific Publishing Co., Amsterdam and New York 1976, pp. 111-134.

3. GAMBERALE, M., ANNWALL, G. and HULTENGREN, M. Exposure to white spirit: II. Psychological functions. Scand. j. work environ. \& health 1 (1975) $31-39$.

4. GAMBERALE, F., ANNWALL, G. and HULTENGREN, M. Exposure to methylene chloride: II. Psychological functions. Scand. j. work environ. \& health 1 (1975) 95-103.

5. GAMBERALE, F. and HULTENGREN, $M$ Toluene exposure: II. Psychophysiological functions. Work-environ.-health 9 (1972) 131-139.

6. GAMBERALE, F. and HULTENGREN, M. Methylchloroform exposure: II. Psychophysiological functions. Work-environ.health 10 (1973) 82-92.

7. GAMBERALE, F., LISPER, H. O. and ANSHELM OLSON, B. The effects of styrene vapour on the reaction time of workers in the plastic boat industry. In: M. HORVÁTH (ed.), Adverse effects of environmental chemicals and psychotropic drugs (vol. 2). Elsevier Scientific Publishing Co., Amsterdam and New York 1976, pp. $135-148$

8. SALVINI, M.. BINASCHI, S. and RIVA, M. Evaluation of the psychophysiological functions in humans exposed to trichloroethylene. $\mathrm{Br}$. j. ind. med. 28 (1971) 293295.

9. SIEGEL, S. Nonparametric statistics for the behavioural sciences. McGraw-Hill Book Co., Tokyo 1956, pp. 166-172.

10. STEWART, R. D., HAKE, C. L., LE BRUN, A. I., KALBFLEISCH, J. H., NEWTON, P. E., PETERSON, J. E., COHEN, H., STRUBE, R. and BUSCH, K. A. Effects of trichloroethylene on behavioral performance capabilities. In: C. XINTARAS, B. L JOHNSON and I. GROOT (eds.). H. E. W. Publication no. (NIOSH) 74-126. U.S. Department of Health, Education and Welfare, Washington D.C. 1974 , pp. 96-129.

11. STOPPS, G. J. and MC LAUGHLIN, M. Psychophysiological testing of human subjects exposed to solvent vapor. $A m$. ind. hyg. assoc. j. 28 (1967) 43-50.

12. WINER, B. J. Statistical principles in experimental design. McGraw Hill Book Co., New York, N.Y. 1970, pp. 539-543, $571-574$. 